\title{
EVALUATION OF SERUM-FREE IRON AND GLYCATED HEMOGLOBIN IN UNCONTROLLED TYPE-II DIABETIC PATIENTS
}

\author{
KAMALAM R, NALINI GANESAN*, ANBAZHAGAN M
}

Department of Biochemistry, Sri Ramachandra Medical College and Research Institute, Sri Ramachandra University, Porur, Chennai, Tamil Nadu, India. Email: nalinisrmc@gmail.com

Received: 23 September 2016, Revised and Accepted: 04 October 2016

\section{ABSTRACT}

Objective: Diabetes mellitus (DM) is a common health problem in the world. Free iron may contribute to the pathogenesis and progress of this disease and its complication. Iron causes hyperinsulinemia by decreasing the insulin uptake and metabolism by hepatocytes. Elevated iron stores are commonly found in insulin resistance. Iron in its free form is known to induce oxidation of biomolecules by producing harmful hydroxyl radicals. In this study, we aimed to estimate and compare the serum levels of free iron in diabetes and healthy individuals.

Methods: This study included 244 subjects in two groups. Group-I comprised 204 subjects with DM and Group-II comprised 40 healthy subjects. Blood sugar, free iron, and glycated hemoglobin were analyzed in blood samples using standard kits. The results of all the parameters were expressed as mean \pm standard deviation. Student $t$-test was done to assess the statistical significance between two groups. The association between the parameters was studied by Pearson correlation.

Results: In this study, we found a significant increase in serum free iron in Group-I ( $<<0.01)$ when compared with Group-II. A significant correlation between the serum free iron and glycated hemoglobin ( $r=0.59 ; \mathrm{p}<0.001)$ and fasting blood sugar $(\mathrm{r}=0.43 ; \mathrm{p}<0.001)$.

Conclusion: The elevated serum free iron in uncontrolled diabetes may contribute to oxidative stress which may be associated with complications of diabetes.

Keywords: Free iron, Glycated hemoglobin, Hyperinsulinemia, Diabetes mellitus.

(C) 2017 The Authors. Published by Innovare Academic Sciences Pvt Ltd. This is an open access article under the CC BY license (http://creativecommons. org/licenses/by/4. 0/) DOI: http://dx.doi.org/10.22159/ajpcr.2017.v10i1.15330

\section{INTRODUCTION}

Iron is a very important transition metal for the cells in the body, and its abnormal homeostasis is associated with the pathogenesis of various chronic diseases, including diabetes $[1,2]$. Iron plays a key role in vital biochemical activities [3]. Iron is potentially hazardous because of its ability to participate in the generation of powerful oxidant species such as hydroxyl radical $[4,5]$. Dietary iron is a critical determinant of body's iron status since once absorbed it is not actively excreted [6,7]. However, the ability of iron to cycle between its two stable oxidation states is also potentially to generate reactive oxygen or nitrogen species (ROS or RNS) such as hydroxyl radical via Fenton's and Haber-Weiss reactions $[3,6,8]$. To control and balance the production of ROSs and RNSs, the cell builds up a set of antioxidants and detoxifying enzymes such as superoxide dismutase, catalyze, and glutathione peroxidase that can scavenge excessive ROSs or RNSs beyond the antioxidant capacity of the organism called oxidative stress is encountered in many pathological conditions such as diabetes and diabetic complications $[3,6,9,10]$. Iron can be released from ferritin by the action of reducing agents that convert $\mathrm{Fe}^{3+}$ into $\mathrm{Fe}^{2+}[11,12]$. Apoferritin, the protein fraction of ferritin that holds oxidized iron molecules. When the concentrations of antioxidants are low, the reducing potential and anaerobiosis progressively increase, facilitating a rapid release of iron from ferritin. The overall result of oxidative reactions is an increase in the availability of free iron from the ferritin $[11,13]$. Iron influences insulin action and it interferes with insulin inhibition of glucose production by the liver [11,14-16]. Hepatic extraction and metabolism of insulin are reduced with increasing iron stores, leading to peripheral hyperinsulinemia. In fact, the initial and most common abnormality seen in iron overload conditions is liver insulin resistance $[11,15]$.
The exact mechanism of iron-induced diabetes is mediated by 3 key mechanisms: "Insulin deficiency, insulin resistance, and hepatic dysfunction" [4,17]. The mechanisms for insulin resistance include the possibility of iron overload causing resistance directly or through hepatic dysfunction. Patients with unexplained hepatic iron overload mostly found to be insulin resistant, which suggests a common etiologic link among hepatic iron, hepatic dysfunction, and insulin resistance [18]. This study was aimed to determine serum free iron in person with diabetes and healthy individuals.

\section{METHODS}

This study was done at the Department of Biochemistry, Sri Ramachandra Medical College and Research Institute, Chennai - 116, and it was approved by our Institutional Ethical Committee (REF: CSP/12/JUL/24/111).

\section{Selection of participants}

The total number of subjects was 244 . Study subjects were categorized into 2 groups.

Diabetes mellitus (DM) group consists of 204 subjects. The exclusion criteria are Type-I DM, hyperthyroidism, cancer, and pancreatitis. Inclusion criteria are Type-2 DM >30 years of age.

The healthy group consists of 40 subjects. Exclusion criteria are smokers, alcoholics, pregnant and lactating women. The inclusion criteria are $>30$ years of healthy persons without any disease.

\section{Sample type}

Serum, plasma, and whole blood. 
Sample collection

The blood sample from 244 individuals was collected in fasting state using vacutainers with sodium fluoride and EDTA and without anticoagulants sterile gel tube. These tubes were centrifuged at $3500 \mathrm{rpm}$ for 10 minutes, and serum was separated.

\section{Blood sample analysis}

Fasting blood sugar (FBS) by hexokinase method and free iron by direct iron assay using chromophore ferene ${ }^{\circledR}$ were analyzed in blood sample using standard kits in Dimension RxL autoanalyzer, USA, and glycated hemoglobin (HbA1c) by high-performance liquid chromatography method was analyzed in blood sample using Bio-rad autoanalyzer, USA. Glucose present in plasma in expressed as mg/dl. Iron present in serum is expressed as $\mu \mathrm{g} \%$. HbA1c present in whole blood is expressed as $\mathrm{g} \%$.

\section{Statistical analysis}

The results of all the parameters were expressed as mean \pm standard deviation. Student $t$-test was done to assess the statistical significance between two groups. The association between the parameters was done by the correlation coefficient.

\section{RESULTS}

Our present study was done on 204 Type-II diabetes and 40 healthy subjects. A direct relationship was found between serum free iron and Type-II DM. We found a significant increase in serum free iron in Group-I 98.33 $\pm 51.27(\mathrm{p}<0.01)$ when compared with Group-II $78.07 \pm 33.13$ (Table 1 )

In this study, we found a significant positive correlation between the serum free iron and FBS (r=0.43; $<<0.001)$ (Fig. 1) and HbA1c $(r=0.59$; $\mathrm{p}<0.001$ ) (Fig. 2), respectively.

\section{DISCUSSION}

In this present study, we have observed a significant increase in serum free iron in Group-I cases, compared to Group-II cases who were in good glycemic control [19]. Hyperglycemia observed in Group-I causes increased glycation of protein and releases the iron in its free state. Several studies have shown that serum free iron is significantly increased in Type-II DM $[20,21]$. This observation is contradicted by the studies of EI-Nabarawy et al. [1]. Glycemic control reflects the interaction between hyperinsulinemia with iron. This is further supported by evidence suggesting that hyperglycemia precedes the elevation of iron in diabetes [22,23].

In this present study, we found a positive correlation between FBS and free iron as well as free iron and $\mathrm{HbA} 1 \mathrm{c}$ in Group I. Increased glycation of proteins as a result of poor glycemic control triggers the increased release of free iron from glycated proteins like hemoglobin which generates a vicious cycle of hyperglycemia, glycation of hemoglobin, and increase in levels of free iron [18]. The relationship between free iron and Type- 2 diabetes is bidirectional [24]. Insulin influences the iron uptake and storage by increasing the cell surface transferring receptors [25], reciprocally iron influences the insulin activity by interfering with glucose uptake and utilization [26]. This increased presence of free iron pool will enhance oxidant generation leading damage to biomolecules [8]. Free iron is known to induce oxidation of biomolecules through Fenton's and Haber-Weiss reaction by producing harmful hydroxyl radicals $[8,24]$. Free radical formation may play a role in the pathogenesis of diabetes by disrupting insulin action and total body glucose disposal. The iron act as a powerful prooxidant and the oxidative stress is increased in glucose-intolerant states [27-29]. The presence of poor glycemic control, hyperglycemia, iron overload, and protein glycation will all lead to oxidative stress causing the early appearance of microvascular complications (retinopathy and nephropathy) $[8,24,30]$. The limitations of the present study, we have not assessed the markers of oxidative stress and insulin resistance.
Table 1:Demographical data and biochemical parameters in the study groups

\begin{tabular}{lll}
\hline Variables & Group I (n=204) & Group II (n=40) \\
\hline Age (in years) & $55.74 \pm 10.72$ & $40.35 \pm 8.83$ \\
Sex (female: male) & $78: 126$ & $27: 13$ \\
FBS (mg\%) & $155.78 \pm 58.20^{* * *}$ & $91.72 \pm 8.82$ \\
HbA1c (g\%) & $8.33 \pm 2.12^{* * *}$ & - \\
Serum free iron $(\mu \mathrm{g} \%)$ & $98.33 \pm 51.27^{* *}$ & $78.07 \pm 33.13$ \\
\hline
\end{tabular}

${ }^{* *} \mathrm{p}<0.01,{ }^{* * *} \mathrm{p}<0.001$. FBS: Fasting blood sugar, HbA1c: Glycated hemoglobin

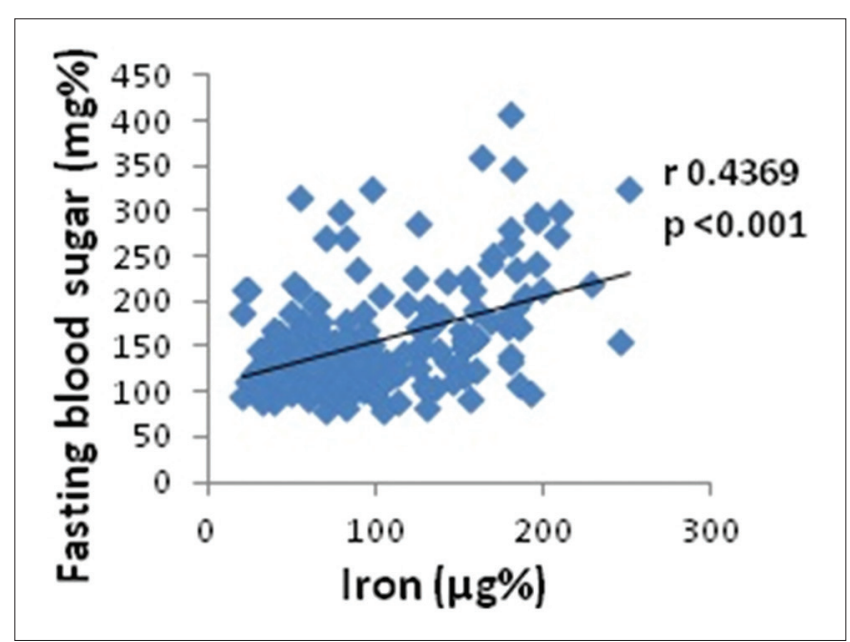

Fig. 1: Correlation between serum free iron and fasting blood sugar in Group-I

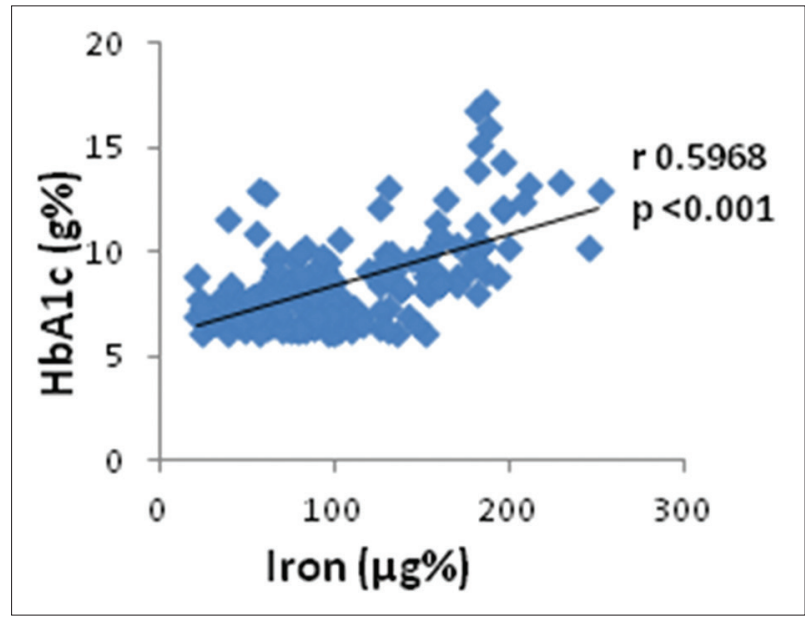

Fig. 2: Correlation between serum free iron and glycated hemoglobin in Group-I

\section{CONCLUSION}

The significantly increased serum free iron and HbA1c in DM reveals the fact that serum free iron contributes indirectly to oxidative stress in DM.

\section{REFERENCES}

1. EI-Nabarawy SK, Mohamed MA, Ahmed MA, El-Arabi GH. $\alpha$-Lipoic acid ameliorates the oxidative status and serum iron in diabetic patients. J Pharm Biomed Sci 2011;1(5):97-103.

2. Shah SV, Fonseca VA. Iron and diabetes revisited. Diabetes Care 2011;34(7):1676-7.

3. Papanikolaou G, Pantopoulos K. Iron metabolism and toxicity. Toxicol 
Appl Pharmacol 2005;202(2):199-211.

4. Swaminathan S, Fonseca VA, Alam MG, Shah SV. The role of iron in diabetes and its complications. Diabetes Care 2007;30(7):1926-33.

5. Halliwell B, Gutteridge JM. Role of free radicals and catalytic meta ions in human disease: An overview. Methods Enzymol 1990;186:1-85.

6. Liu Q, Sun L, Tan Y, Wang G, Lin X, Cai L. Role of iron deficiency and overload in the pathogenesis of diabetes and diabetic complications. Curr Med Chem 2009;16(1):113-29.

7. Beutler E, Hoffbrand AV, Cook JD. Iron deficiency and overload. Hematology Am Soc Hematol Educ Program 2003:40-61.

8. Shetty JK, Prakash M, Ibrahim MS. Relationship between free iron and glycated hemoglobin in uncontrolled Type 2 diabetes patients associated with complications. Indian J Clin Biochem 2008;23(1):67-70.

9. Eaton JW, Qian M. Molecular bases of cellular iron toxicity. Free Radic Biol Med 2002;32(9):833-40.

10. Chitra V, Venkata KR, Varma P, Raju MV, Prakash KJ. Study of antidiabetic and free radical scavenging activity of the seed extract of strychnos nuxvomica. Int J Pharm Pharm Sci 2010;2(1):106-10.

11. Fernández-Real JM, López-Bermejo A, Ricart W. Cross-talk between iron metabolism and diabetes. Diabetes 2002;51(8):2348-54.

12. Reif DW. Ferritin as a source of iron for oxidative damage. Free Radic Biol Med 1992;12(5):417-27.

13. Juckett MB, Balla J, Balla G, Jessurun J, Jacob HS, Vercellotti GM Ferritin protects endothelial cells from oxidized low density lipoprotein in vitro. Am J Pathol 1995;147(3):782-9.

14. Forouhi NG, Harding AH, Allison M, Sandhu MS, Welch A, Luben R, et al. Elevated serum ferritin levels predict new-onset Type 2 diabetes: Results from the EPIC-Norfolk prospective study. Diabetologia 2007;50(5):949-56.

15. Sharifi F, Ziaee A, Feizi A, Mousavinasab N, Anjomshoaa A, Mokhtari P Serum ferritin concentration in gestational diabetes mellitus and risk of subsequent development of early postpartum diabetes mellitus. Diabetes Metab Syndr Obes 2010;3:413-9.

16. Jehn ML, Guallar E, Clark JM, Couper D, Duncan BB, Ballantyne CM, et al. A prospective study of plasma ferritin level and incident diabetes: The Atherosclerosis Risk in Communities (ARIC) Study. Am J Epidemiol 2007;165(9):1047-54.

17. Cooksey RC, Jouihan HA, Ajioka RS, Hazel MW, Jones DL, Kushner JP, et al. Oxidative stress, beta-cell apoptosis, and decreased insulin secretory capacity in mouse models of hemochromatosis. Endocrinology 2004;145(11):5305-12.
18. Brudevold R, Hole T, Hammerstrøm J. Hyperferritinemia is associated with insulin resistance and fatty liver in patients without iron overload. PLoS One 2008;3(10):e3547.

19. Kamalam R, Ganesan N, Anbazhagan M. Effect of Free Iron and Glycated Haemoglobin in Uncontrolled Type-II Diabetic Patients. $33^{\text {rd }}$ Annual Conference of Indian Association of Biomedical Scientists(IABMS), Host: Nitte University, Mangalore, $3^{\text {rd }}$ November, 2012 .

20. Senghor A, Bhrathya N, Kumar JS, William E, Balasubramaniam. Serum ferritin, iron, TIBC, hemoglobi $\mathrm{n}$ in male patients with dysglycemia. Int J Biol Med Res 2012;3(2):1609-11.

21. Zafar U, Qureshi HJ, Karim A. Insulin resistance and serum parameters of iron status in Type 2 diabetics. Pak J Physiol 2011;7(2):28-31.

22. Thomas MC, MacIsaac RJ, Tsalamandris C, Jerums G. Elevated iron indices in patients with diabetes. Diabet Med 2004;21(7):798-802.

23. Shi Z, Zhou M, Yuan B, Qi L, Dai Y, Luo Y, et al. Iron intake and body iron stores, anaemia and risk of hyperglycaemia among Chinese adults: The prospective Jiangsu Nutrition Study (JIN). Public Health Nutr 2010;13(9):1319-27.

24. Maitreyees DS. Study of free iron, superoxide dismutase, malondialdehyde and glycated hemoglobin in Type 2 diabetes mellitus with and without microvascular complications. 2011.

25. Tanner LI, Lienhard GE. Localization of transferrin receptors and insulin like growth factor II receptors in vesicles from 3T3L1 adipocytes that contain intracellular transporters. J Cell Bio 1989;108(4):1537-45.

26. Niederau C, Berger M, Stremmel W, Starke A, Strohmeyer G, Ebert R, et al. Hyperinsulinaemia in non-cirrhotic haemochromatosis: Impaired hepatic insulin degradation? Diabetologia 1984;26(6):441-4.

27. Fujita N, Miyachi H, Tanaka H, Takeo M, Nakagawa N, Kobayashi Y et al. Iron overload is associated with hepatic oxidative damage to DNA in nonalcoholic steatohepatitis. Cancer Epidemiol Biomarkers Prev 2009; 18(2):424-32.

28. Ford ES, Cogswell ME. Diabetes and serum ferritin concentration among U.S. Adults. Diabetes Care 1999;22(12):1978-83.

29. Arredondo M, Jorquera D, Carrasco E, Albala C, Hertrampf E. Microsatellite polymorphism in the heme oxygenase-1 gene promote is associated with iron status in persons with Type 2 diabetes mellitus. Am J Clin Nutr 2007;86(5):1347-53

30. Jain R, Jain P, Jain P. A review on treatment and prevention of diabetes mellitus. Int J Curr Pharm Res 2016;8(3):16-8 